\title{
Segment 2 based characterization of a novel I ndian Bluetongue virus isolate
}

\author{
Minakshi Prasad, Koushlesh Ranjan, Pawan Kumar and Gaya Prasad
}

Department of Animal Biotechnology,

LLR University of Veterinary and Animal Sciences, Hisar, Haryana, 125004 India

Corresponding author: Minakshi Prasad, email:minakshi.abt@gmail.com

Received: 04-09-2012, Accepted: 29-09-2012, Published online: 06-02-2013

\section{How to cite this article:}

Prasad M, Ranjan K, Kumar P and Prasad G (2013) Segment 2 based characterization of a novel Indian bluetongue virus isolate, Vet. World 6(5):244-248, doi: 10.5455/vetworld.2013.244-248

\begin{abstract}
Aim: The study was conducted to characterize and serotype the novel isolate of bluetongue virus (BTV) isolated from India.

Materials and Methods: The BTV isolate was propagated in BHK-21 cell line. Nucleic acid (dsRNA) was extracted using Trizol method and cDNA was prepared using a process called reverse transcription. The cDNA was subjected to group specific PCR using ns1 gene specific primer to confirm the isolate as BTV. The type specific PCR was conducted to confirm the serotype of the virus using vp2 gene specific primers for all the BTV serotype including BTV10. The vp2 gene specific PCR amplicon was sequenced and in-silico restriction enzyme analysis and phylogenetic analysis was conducted.

Results: Group specific PCR using ns1 gene specific primers showed a single 274bp amplicon in agarose gel electrophoresis confirmed the sample as BTV. The type specific PCR using BTV10 vp2 gene specific primer showed a single amplicon of 647bp. Remaining BTV serotype specific primers didn't show any amplification. The vp2 gene PCR amplicon was sequenced. The in-silico restriction enzyme analysis of vp2 gene of Indian BTV10 isolate along with other isolates from GenBank database using HindIII, XhoII and ApoI showed a common pattern between Indian and USA isolates. Similarly, phylogenetic analyses using vp2 gene nucleotide as well as deduced amino acid sequence of Indian BTV10 isolate and global isolates showed that Indian and most of the USA isolates placed in a single clad.
\end{abstract}

Conclusion: A novel BTV isolate was isolated and confirmed as BTV serotype 10. Upon molecular analysis Indian BTV10 isolate was found closer to that of USA isolates than other global isolates.

Key words: bluetongue, BTV10, PCR, restriction enzyme analysis, vp2 gene

\section{I ntroduction}

Bluetongue (BT) is an infectious, non contagious arthropod borne viral disease of wild and domestic ruminants especially sheep. The disease is caused by bluetongue virus (BTV) the type species of the genus Orbivirus and belongs to family Reoviridae [1]. BTV infects most of the domestic and wild ruminant and causes BT disease primarily in sheep characterised by severe clinical signs such as fever, lameness (coronitis), swelling and cyanosis of lips and tongue leading to death. It is listed as a 'notifiable disease' by the Office International des Epizooties [2].

The disease occurs as more severe form in sheep [3]. Occasionally Severe forms of clinical signs and mortalities can be observed in goats and camelids [4]. Cattle act as reservoirs for virus and remain viraemic for several months and spread virus through insect vector [5]. Subclinical form of infection can also cause loss of condition, reduced milk yield, abortion leading to infertility [6]. Therefore mandatory export restrictions and the surveillance requirements are imposed on movement of ruminants and other animal products of BT endemic countries to BT free countries [7].

BTV consists of double-stranded RNA (dsRNA) ten segmented linear genome which encode 7 structural proteins (VP1 to VP7) organised into two concrete shells i.e., the inner and outer capsid and 4 non-structural proteins (NS1, NS2, NS3 and NS3a).

Till 2008, twenty four distinct serotypes of BTV have been isolated and characterised worldwide [1]. However, recently two more proposed serotypes i.e. BTV-25 from Switzerland [8] and BTV-26 from Kuwait [9] have been reported. A total of 21 different BTV serotypes have been reported from different parts of Indian subcontinent based upon serology and virus isolation [10]. However, in recent past BTV serotype 21 has been isolated from West Bengal state of India [11]. In the present study a virus isolated from sheep suspected for BT disease from Andhra Pradesh was undertaken for typing and characterization studies.

\section{Materials and Methods}

Sample preparation: The BTV isolate used in present study was isolated from Andhra Pradesh state. The virus was grown in confluent monolayer of BHK 21 cell line to raise the stock. After appearance of complete CPE in infected BHK-21 cell line, the infected cells were harvested and pelleted at $3,000 \mathrm{X} \mathrm{g}$ for 10 minutes in table top centrifuge (REMI, India). The supernatant was decanted carefully and viral dsRNA was extracted from pelleted material using Guanidinium isothiocynate method [12]. The extracted viral RNA was screened by RNA-PAGE followed by 


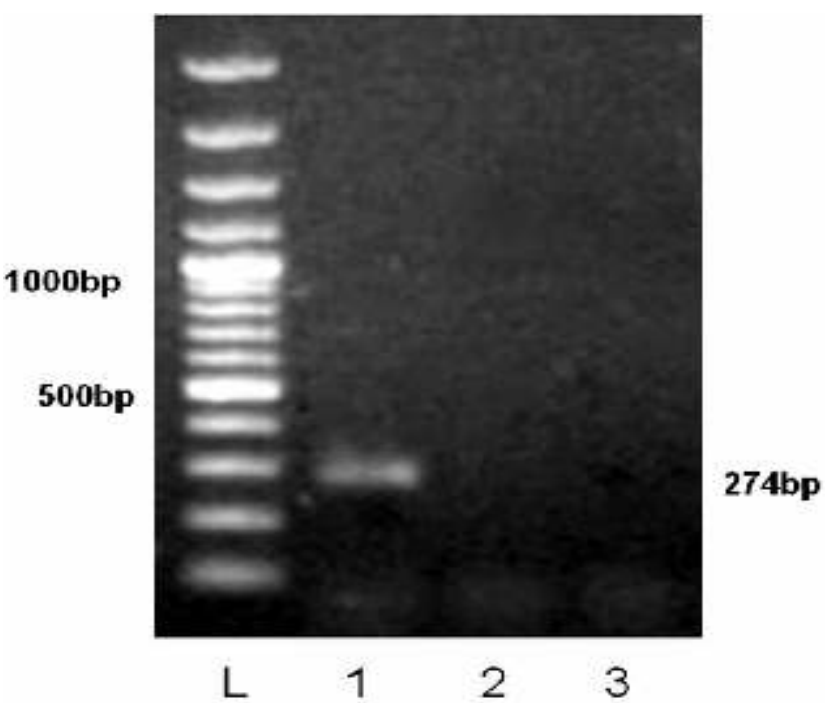

Figure-1. Ns1 gene specific RT-PCR of Indian isolate of BTV10 showing amplicon size of $274 \mathrm{bp}$. Lane L: Ladder $100 \mathrm{bp}$, Lane 1: BTV10 isolate.

silver staining to visualize the 10 dsRNA segments for confirmation as BTV.

Amplification of BT viral genes by RT-PCR for confirmation of BT isolate: The BT viral genomic dsRNA was used as template for cDNA synthesis using random decamer primer (Ambion, USA) in thermal cycler (Biorad i Cycler $\left.{ }^{\circledR}\right)$. For $50 \mu \mathrm{l}$ reaction mixture, $7 \mu \mathrm{g}$ of viral dsRNA was subjected to heat denaturation along with $6 \%$ DMSO and $30 \mathrm{pM}$ of random primer then finally $400 \mu \mathrm{M}$ each dNTPs and $500 \mathrm{U}$ of MoMuLV reverse transcriptase (Promega) for reverse transcription was added. The primer was subjected to anneal at $25^{\circ} \mathrm{C}$ for $10 \mathrm{~min}$, reverse transcription at $37^{\circ} \mathrm{C}$ for $60 \mathrm{~min}$ and finally heat inactivation at $90^{\circ} \mathrm{C}$ for 10 $\min$.

The group specific PCR was carried out to confirm the presence of BT viral genome in the sample. The cDNA obtained was subjected to ns 1 gene specific PCR primers $\mathrm{P} 1$ and P2 (P1(11-31): 5'GTTCTCTA GT TGGCAACCACC3' and P2: (284-265): 5' AAGC CA GACTGTTTCCCGA 3') to generate an amplicon of 274bp size [13].

Determination of serotype of BT isolate by using type specific primers: The cDNA was further subjected to type specific PCR using all 24 serotype specific vp2 gene based primers. A total of 24 PCR reactions were carried out using serotype 1-24 type specific primers individually in $20 \mu \mathrm{l}$ reaction mixture. Each reaction mixture contained $2 \mu \mathrm{l}$ cDNA, 3\% DMSO, $20 \mu \mathrm{M}$ of type specific primer pair along with $0.4 \mu \mathrm{l}$ of $10 \mathrm{mM}$ dNTPs mix (Finnzyme), $4 \mu 15 \mathrm{X}$ HF buffer and $0.4 \mathrm{U}$ $(2 \mathrm{U} / \mu \mathrm{l})$ phusion $^{\circledR}$ high- fidelity DNA polymerase (Finnzyme) in thermalcycler (Biorad iCycler ${ }^{\circledR}$ ). The amplification programme consisted of initial denaturation for $3 \mathrm{~min}$ at $98^{\circ} \mathrm{C}$, followed by 32 cycles for $10 \mathrm{sec}$ denaturation at $98^{\circ} \mathrm{C}, 20 \mathrm{sec}$ primer extension at $72^{\circ} \mathrm{C}$ and annealing at $56^{\circ} \mathrm{C}$ for $20 \mathrm{sec}$. Final primer extension was carried out at $72^{\circ} \mathrm{C}$ for 10

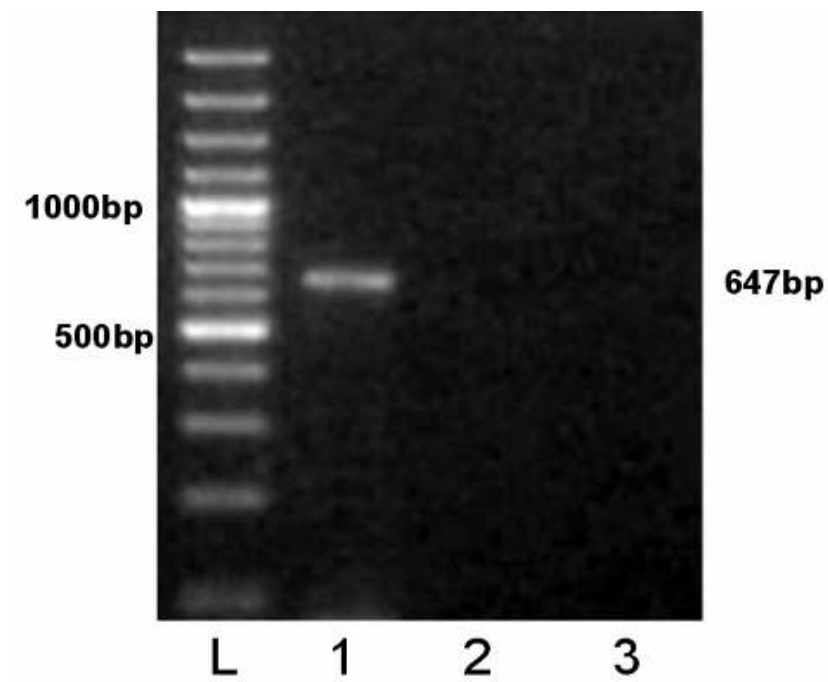

Figure-2. Vp2 gene specific RT-PCR of Indian isolate of BTV10 showing amplicon size of $647 \mathrm{bp}$. Lane L: Ladder $100 \mathrm{bp}$, Lane 1: BTV10 isolate.

minute. All the PCR products were visualised by agarose gel electrophoresis under UV light in gel documentation system (Biovis, USA).

Nucleotide sequence based characterization of BT isolate: The serotype 10 specific PCR product was purified using QIA quick gel extraction kit ${ }^{\circledR}$ (QIAGEN) as per manufacturers' instructions. The purified PCR product was further amplified using BigDye Terminator sequencing $\mathrm{kit}^{\circledR}$ (ABI, USA) as per manufacturers' instructions. The amplified product was purified, precipitated and dissolved in Hi-Di formamide (ABI, USA). The dissolved product was transferred to sequencing plate and subjected to sequencing in DNA analyzer (ABI PRISM ${ }^{\text {TM }} 3130$ Version 3.0) in the Department. The sequencing data was collected and subjected to sequence analysis using online software BLASTN+ 2.2.27 (http://blast.ncbi. nlm.nih.gov/) [14]. The nucleotide sequences were converted to deduced amino acid sequences based on open reading frame. Bioedit v7.0.8 software [15] was used for multiple sequence alignment and percent identity calculation of partial vp2 gene nucleotide as well as deduced amino acid sequences along with other global sequences of BTV10 obtained from GenBank database.

Phylogenetic tree was constructed based on nucleotide as well as deduced amino acid sequences for the Indian BT isolate with other global isolates using Mega 5 software [16]. Restriction mapper version 3.0 (http://www.restrictionmapper.org/) software was used for in-silico restriction analysis of Partial vp2 gene of BTV isolates from India and different parts of the world.

\section{Results and Discussion}

India is vast country with tropical climate and prevalence of Culicoides spp. The viral antibodies have been reported from domestic and wild ruminants in the 
Table-1. Percent nucleotide and amino acid sequence identity of vp2 gene of BTV 10 (2124-2611bp nucleotides and its corresponding amino acids)

\begin{tabular}{lcc}
\hline BTV10 isolates & $\begin{array}{c}\text { J F303890.1(BTV10.IND) } \\
\text { nucleotides }\end{array}$ & $\begin{array}{c}\text { J F303890.1(BTV10.IND) } \\
\text { deduced amino acids }\end{array}$ \\
\hline JF303890.1(BTV10.IND) & 100 & 100 \\
JQ740772.1(BTV10.IND) & 100 & 100 \\
JF727655.1(BTV10.IND) & 99.7 & 100 \\
U06786.1 (BTV10 USA) & 100 & 100 \\
L29027.1(BTV10 USA) & 100 & 100 \\
L29026.1(BTV10 USA) & 100 & 100 \\
M11787.1(BTV10 USA) & 100 & 100 \\
U06783.1(BTV10 USA) & 99.5 & 100 \\
U06782.1(BTV10 USA) & 99.3 & 100 \\
U06780.1(BTV10 USA) & 99.3 & 100 \\
U06781.1(BTV10 USA) & 96.3 & 97.5 \\
U06785.1(BTV10 USA) & 95.9 & 97.5 \\
U0678.1(BTV10 USA) & 95.6 & 98.1 \\
AJ585131.1 (BTV10R.S.A.) & 88.7 & 91.3 \\
HQ222821.1(BTV10 FRA) & 89.5 & 93.2 \\
\hline
\end{tabular}

I ND=India, RSA= South Africa, FRA=France

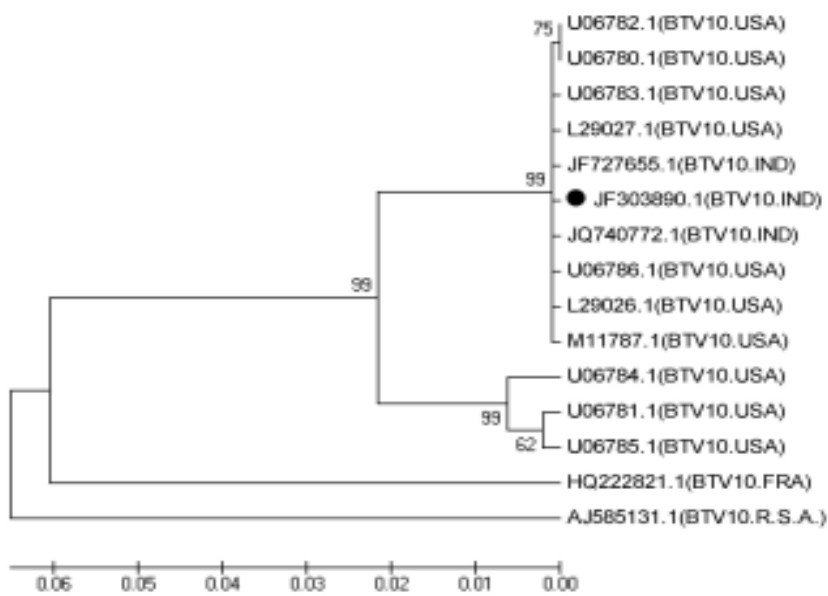

Figure-3. Phylogenetic tree of BTV10 isolates based on partial vp2 gene nucleotide sequences. Tree was constructed from partial nucleotide sequences of vp2 gene using the neighbour joining method in Mega5 software programme with default parameters. Numbers at the major nodes indicate the bootstrap values.

country [17]. Different serotype specific antibodies of BTV that have been reported so far from various parts of India are 1, 2, 3, 4, 5, 6,7, 8,9, 10., 11, 12, 13, 14, 15, $16,17,18,19,20,21$ and 23 [10]. The virus isolated in cell culture have been listed as BTV serotypes 1, 2, 3, 4, $8,9,12,16,17,18,21,23$ but not $5,6,7,10,11,13,14$, $15,19,20,22$ and 24 . In the present study, a BTV isolate of sheep origin adapted in BHK21 cell line was isolated from sheep of Andhra Pradesh was typed and characterized.

The dsRNA extracted from cell culture grown virus was screened by RNA-PAGE and silver staining showed presence of 10 dsRNA segments arranged in 3:3:3:1 pattern typical of BTV (data not shown). The viral RNA was further subjected to ns1 gene specific RT-PCR. This group specific RT-PCR showed a single $274 \mathrm{bp}$ amplicon of expected size confirmed the sample as positive for BTV (Fig. 1). After confirming the sample as BTV isolate, the sample was subjected to typing PCR to determine the serotype it possessed using 24 serotype specific primer pairs based on vp2 gene. A single expected 648b amplicon size was observed without any nonspecific amplification in $1 \%$ agarose gel electrophoresis (LifeTech. USA) (Fig. 2). There was no amplification with remaining twenty three serotype specific primers. The isolate was typed
Table-2. In-silico restriction analysis of BTV 10 isolates from different parts of the world

\begin{tabular}{llll}
\hline BTV 10 isolates & HindIII & Xholl & A pol \\
\hline JF303890.1(BTV10 IND) & 2148 & 2478 & 2179,2438 \\
JQ740772.1(BTV10.IND) & 2148 & 2478 & 2179,2438 \\
JF727655.1(BTV10.IND) & 2148 & 2478 & 2179,2438 \\
L29026.1 (BTV10 USA) & 2148 & 2478 & 2179,2438 \\
L29027.1 (BTV10 USA) & 2148 & 2478 & 2179,2438 \\
M11787.1 (BTV10 USA) & 2148 & 2478 & 2179,2438 \\
U06780.1 (BTV10 USA) & 2148 & 2478 & 2179,2438 \\
U06782.1 (BTV10 USA) & 2148 & 2478 & 2179,2438 \\
U06783.1 (BTV10 USA) & 2148 & 2478 & 2179,2438 \\
U06786.1 (BTV10 USA) & 2148 & 2478 & 2179,2438 \\
U06781.1 (BTV10 USA) & 2148 & 2478 & 2438 \\
U06784.1 (BTV10 USA) & 2148 & 2478 & 2438 \\
U06785.1 (BTV10 USA) & 2148 & 2478 & 2438 \\
AJ585131.1 (BTV10R.S.A.) & - & - & 2179,2478 \\
HQ222821.1 (BTV10 FRA) & 2148 & - & $2179,2438,2478$ \\
\hline
\end{tabular}

IND=India, RSA= South Africa, FRA=France

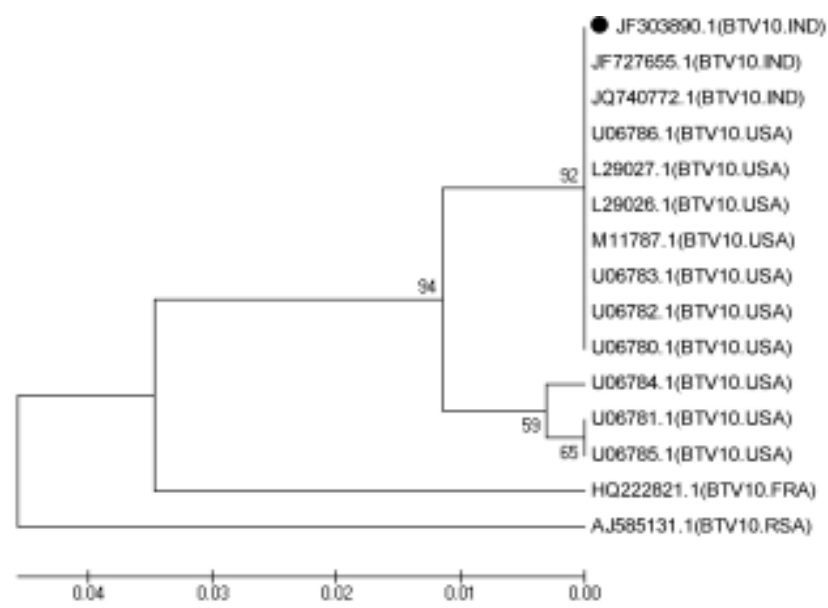

Figure-4. Phylogenetic tree of BTV10 isolates based on partial vp2 gene amino acid sequences. Tree was constructed from partial amino acid sequences of vp2 gene using the neighbour joining method in Mega5 software programme with default parameters. Numbers at the major nodes indicate the bootstrap values.

as BTV10, a novel serotype not isolated in BHK21 cell line earlier at BTV typing centre Hisar so far.

The PCR product of BTV 10 was allowed for direct sequencing and the nucleotide sequence obtained was deposited to GenBank database and an accession no. JF303890.1 was assigned. The sequence data was further analysed to determine the identity of this isolate with rest of the global isolated in the genBank using Bioedit v7.0.8 software programme (Table-1). The data analysis showed that novel BTV10 isolate (JF303890.1_BTV10 IND) share 100\% nucleotide sequence identity with four USA isolates (GenBank accession nos. U06786.1, L29027.1, L29026.1 and M11787.1) and one of the Indian isolate (GenBank accession nos. JQ740772.1). However, it showed more than 95\% nucleotide identity with six other USA isolates (GenBank accession nos. U06780.1, U06781.1, U06782.1, U06783.1, U06784.1 and U06785.1) and one Indian isolate (GenBank accession nos. JF727655.1). While, novel BTV10 isolate showed only $88.7 \%$ and $89.5 \%$ nucleotide identity with South Africa and France BTV 10 isolate.

The nucleotide sequences of the BTV10 isolate was deduced into corresponding amino acid sequences according to open reading frame (ORF). The percent amino acid sequence identity was determined using 
Bioedit v7.0.8 software programme and the result was coincidental with nucleotide based identity (Table 1). It was observed that novel BTV 10 isolate showed $100 \%$ amino acid identity with seven of USA isolates (Gen Bank accession nos.U06786.1, L29027.1, L29026.1, M11787.1, U06783.1, U06782.1, and U06780.1) and two Indian isolate (GenBank accession nos. JQ740772.1 and JF727655.1). However, it showed more than $99 \%$ identity with three other USA isolates (GenBank accession nos.U06781.1, U06785.1 and U06784.1). However, Indian isolate showed 91.3\% and $93.2 \%$ identity with South Africa and France isolate.

Phylogenetic tree was constructed based on nucleotides as well as deduced amino acids sequences of novel BTV 10 isolate (JF303890.1_BTV10 IND) with other isolates available in GenBank using Mega 5 software programme (Fig. 3 and 4). The novel BTV10 isolate formed close cluster with Indian isolate (GenBank accession nos. JQ740772.1 and JF727655.1) and most of the USA isolates and was closer to minor cluster obtained from three other USA isolates (GenBank accession nos.U06781.1, U06785.1 and U06784.1). However, novel isolate BTV10 was found distantly related to South African (AJ585131.1 _BTV10 R.S.A.) and France (HQ222821.1_BTV10 FRA) isolates. The phylogenetic trees generated on the basis of analysis of nucleotide sequences and amino acid sequences generated similar type of findings except the amino acid generated tree showed more closeness of the isolates in major clad than that of nucleotide generated tree (Fig3 and 4).

The in- silico restriction analysis of novel BTV 10 (JF303890.1_BTV10 IND) and other isolates available in GenBank with Hind III, XhoII and ApoI restriction enzyme was done using online software programme restriction mapper version 3.0 (http://www. restriction mapper.org/) (Table-2). The in-silico restriction enzyme analysis revealed a single restriction site for Hind III and XhoII at $2148 \mathrm{nt}$ and $2478 \mathrm{nt}$ respectively in all the isolates from India and USA. However, in France isolate XhoII restriction site was absent where as Hind III restriction site was found at 2148nt. The restriction sites of enzymes Hind III and XhoII were completely absent in South African isolate.

Similarly, in -silico restriction analysis with ApoI showed two restriction sites at 2179nt and 2438nt in all the Indian, USA and France isolates except three of the USA isolates (GenBank accession nos. U06781.1, U06784.1 and U06785.1) which had only one ApoI site at $2438 \mathrm{nt}$. The France isolate showed one additional ApoI site at 2478nt along with other restrictions sites at 2179nt and 2438nt. The south Africa BTV 10 isolate possed the same ApoI restriction site at 2179nt and $2478 \mathrm{nt}$. The results of in- silico restriction enzyme analysis and phylogenetic analysis thus depicted that novel isolate BTV10 is closer to Indian and USA isolates as compared to France and South African isolates. In Indian subcontinent, though the previous studies in1982 have shown the presence of antibodies for BTV10 serotype $[18,19]$ but no reports of virus isolation have been observed till 2011. However, recently BTV10 was reported from Andhra Pradesh. The partial nucleotide sequence analysis revealed that the isolate in study showed $99.7 \%$ identity with one of the Indian isolate [20] and $100 \%$ identity with one another Indian isolate [21] as well as four USA isolates. Similarly deduced partial amino acid sequence based analysis revealed $100 \%$ identity with above two isolates and USA isolates. The BTV 10 is prevalent in American continent since 1970s [22] but it is recently reported from India. Therefore, the present study suggested that BTV 10 serotype could have been migrated to India from the USA through illegal import of live vaccines or animals infected with low doses of BTV10 or vaccinated with live virus vaccines. However it is difficult to say how and when this had happened. The $100 \%$ identity of the Indian BTV10 isolate used under present study with USA vaccine isolate (GenBank accession no. U06786.1) along with few other BTV10 isolates of sheep origin in USA is supportive of the hypothesis. These findings speculate the increased incidences and severity of the disease in local Indian sheep breeds in near future.

\section{Conclusion}

A novel BT virus isolate from in India was typed and characterized as BTV serotype 10. Since India is endemic for BTV a large number of BTV serotypes are circulating in the country. Many of these viruses including novel BTV10 might have get entry into India though import of animals (infected or vaccinated with live virus vaccine) alone or along with vectors directly from USA to India or indirectly from USA to the neighbouring countries and then in India.. Therefore to control the disease in the country suitable measures should be adopted having facility for control on importation of animal and animal's products and live vaccines.

\section{Authors' contribution}

All the authors have contributed equally. All author read and approved the final manuscript.

\section{Acknowledgements}

The authors are thankful to All India Network Programme on BT (AINP-BT), funded by Indian Council of Agriculture Research, New Delhi for financial support and Department of Animal Biotechnology and College of Veterinary Sciences for providing infrastructural support to carry out a part of this study.

\section{Competing interests}

Authors declare that they have no competing interest.

\section{References}

1. Mertens, P.P.C., Maan, S., Samuel, A. and Attoui,, H. (2005) Orbivirus Reoviridae. In: Fauquet CM, Mayo MA, Maniloff J, Desselberger U, Ball LA, eds. Virus Taxonomy VIIIth 
Report of the ICTV Elsevier/Academic Press London. Pp 466-483.

2. OIE (2006) Manual of Diagnostic Tests and Vaccines for Terrestrial Animals. 6th Ed, Chapter 219 Paris.

3. Darpel, K, E., Batten, C, A., Veronesi, E., Shaw, A.E., Anthony, S., et al. (2007) A study of British sheep and cattle infected with bluetongue virus serotype 8 from the 2006 outbreak in northern Europe. Vet Rec. 161:253-261.

4. Henrich, M., Reinacher, M. and Hamann, H.P. (2007) Lethal bluetongue virus infection in an alpaca. Vet Rec. 161: 764.

5. Maclachlan, N.J., Drew, C.P., Darpel, K.E. and Worwa, G, (2009) The Pathology and Pathogenesis of Bluetongue. $J$ Comp Path. 141: 1-16.

6. Osburn, B.I. (1994) Bluetongue virus. Vet Clin North Am FoodAnim Pract. 10: 547-560.

7. Velthuis AG, Saatkamp HW, Mourits MC, de Koeijer AA, Elbers AR (2009) Financial consequences of the Dutch bluetongue serotype 8 epidemics of 2006 and 2007. Prev Vet Med 93:294-304.

8. Hofmann, M.A., Renzullo, S., Mader, M., Chaignat, V., Worwa, G. and Thuer, B. (2008) Genetic Characterization of Toggenburg Orbivirus, a New Bluetongue Virus, from Goats, Switzerland. Emerg. Infect. Dis. 14 (12): 1855-1861.

9. Maan, S., Maan, N.S., Nomikou, K., Eva, V., Bankowska, K.B., Manjunatha, B.N., Houssam, A. and Mertens, P.P.C. (2011) Complete Genome Characterisation of a Novel 26th Bluetongue Virus Serotype from Kuwait. PlosOne., 6 (10): 1-11.

10. Prasad, G., Minakshi and Malik, Y (2007) 'Bluetongue' (Eds: G. Prasad, Minakshi and Yashpal Malik), A book published by Indian Council of Agricultural Research, New Delhi.

11. Jordar, S.N., Lodh, C., Chakrabarti, A., Baksi, S. and Aich, R. (2009) Isolation of Bluetongue virus serotype 15 and 21 in West Bengal, India. Vet.Rec. 165: 751-752.

12. Chomoczynski, P. and Sacchi, N. (1987) Single step method of RNA isolation by acid Guanidinium isothiocyanate phenol - chloroform extraction. Analit. Biochem. 162: 156159.

13. Prasad, G., Minakshi, Malik, Y. and Maan, S. (1999) RT-
PCR and its detection limit for cell culture grown bluetongue virus1 using NSI gene specific primers. Indian J. Exp. Biol. 37: $1255-1258$.

14. Zhang, Z., Schwartz, S., Wagner,L.and Miller, W. (2000) A greedy algorithm for aligning DNA sequences. J. Comput. Biol.7(1-2):203-14.

15. Hall, T.A. (1999) BioEdit: a user-friendly biological sequence alignment editor and analysis program for Windows 95/98/NT. Nucl. Acids. Symp. Ser. 41:95-98.

16. Tamura, K., Peterson, D., Peterson, N., Stecher, G., Nei, M., and Kumar, S. (2011) MEGA5: Molecular Evolutionary Genetics Analysis using Maximum Likelihood, Evolutionary Distance, and Maximum Parsimony Methods. Mol. Biol. Evo. 28: 2731-2739.

17. Prasad G, Malik P, Malik PK and Minakshi (1998) Serological survey of Bluetongue virus antibodies in domestic and wild ruminants in and around Sariska tiger reserve, Rajasthan. Indian Journal of Virology, 14: 51-53.

18. Choudhary, P.G. (1982) Incidence of bluetongue in State of Maharashtra. In: M.L.Mehrotra (ed.), Proceedings of National Workshop on Bluetongue. Izatnagar: IVRI. 153-8.

19. Sriguppi, B.S. (1982) A note on seroepidemiology of bluetongue. In: M.L. Mehrotra (ed.), Proceedings of National Workshop on Bluetongue. Izatnagar: IVRI. 114-22.

20. Gollapalli, S.R., Mallavarapu, S., Uma, M., Rao, P.P., Susmitha, B., Prasad, P.U., Chaitanya, P., Prasad, G., Hegde, N.R. and Reddy YN. (2012) Sequences of genes encoding type-specific and group-specific antigens of an Indian isolate of bluetongue virus serotype 10 (BTV-10) and implications for their origin. Transbound Emerg Dis. 59(2):165-72.

21. Maan,S., Maan, N.S.,Pullinger, G., Nomikou,K., Morecroft,E., Guimera, M., Belaganahalli, M.N. and Mertens.P.P.C. (2012) The Genome Sequence of Bluetongue Virus Type 10 from India:Evidence for Circulation of a Western Topotype Vaccine Strain. J. Virol. 86(10):5971.

22. Barber, T.L. (1979) Temporal appearance, geographic distribution, and species of origin of bluetongue virus serotypes in the United States. Am. J. Vet. Res. 40: 1654-6.

$* * * * * * * *$ 